\title{
Effect of dietary fish oil supplementation on cellular adhesion molecule expression and tissue myeloperoxidase activity in diabetic mice with sepsis
}

\author{
Wan-Chun Chiu ${ }^{1}$, Yu-Chen Hou ${ }^{2}$, Chiu-Li Yeh ${ }^{2}$, Ya-Mei $\mathrm{Hu}^{2}$ and Sung-Ling $\mathrm{Yeh}^{2} *$ \\ ${ }^{1}$ Graduate Institute of Pharmacy, Taipei Medical University, $250 \mathrm{Wu}$-Hsing Street, Taipei, Taiwan, ROC \\ ${ }^{2}$ Institute of Nutrition and Health Sciences, Taipei Medical University, 250 Wu-Hsing Street, Taipei, Taiwan, ROC \\ (Received 1 September 2006 - Revised 15 November 2006 - Accepted 16 November 2006)
}

\begin{abstract}
This study investigated the effect of $n-3$ fatty acids on adhesion molecules and tissue myeloperoxidase (MPO) activity in diabetic mice with sepsis. Diabetes was induced by a streptozotocin injection. Mice with blood glucose levels exceeding $2000 \mathrm{mg} / 1 \mathrm{were}$ considered diabetic. Diabetic mice were assigned to two groups with a medium-fat $(10 \%, \mathrm{w} / \mathrm{w})$ diet either provided by soyabean oil (SO, $n$ 30) or fish oil (FO, $n 30) . n-3$ fatty acids provided $4.3 \%$ of the total energy and the $n-3 / n-6$ fatty acid ratio was 1:2 in the FO diet. After feeding the respective diet for 3 weeks, all mice had sepsis induced by caecal ligation and puncture (CLP) and were killed at 0,6 or $24 \mathrm{~h}$ after CLP, with ten mice at each time-point. The result showed that compared with the SO group, FO group had lower $\mathrm{PGE}_{2}$ and TNF- $\alpha$ levels in peritoneal lavage fluid after CLP. Lymphocyte CD11a/CD18 expressions were higher at $6 \mathrm{~h}$, whereas the percentage was lower at $24 \mathrm{~h}$ in the SO group than in the FO group. Neutrophil CD11b/CD18 expressions were significantly higher in the SO group than in the FO group at $0 \mathrm{~h}$. The FO group had lower organ MPO activities at various time-points after CLP when compared with those of the SO group. The present findings suggest that compared with the diabetic mice fed SO, a low-dose n-3 fatty acid supplementation may attenuate leucocyte adhesion and infiltration into tissues in diabetic mice complicated with sepsis.
\end{abstract}

Diabetes: Sepsis: Fish oil: Cellular adhesion molecule: Myeloperoxidase

Diabetes mellitus was the fourth leading cause of death in Taiwan in 2005 (Department of Health, Taiwan, 2005). It is a metabolic disorder characterized by hyperglycaemia and dyslipidaemia. Many diabetic patients have an increased risk of CHD, peripheral vascular diseases and cerebrovascular diseases (Parillo \& Riccardi, 2004). Endothelium dysfunction accompanied by upregulated inflammatory mediators is a major contributing factor to the pathogenesis of diabetic vascular complications (Nystrom et al. 2006). Furthermore, the abnormalities in nutrient metabolism resulting from diabetes mellitus lead to impairment of wound healing and vulnerability to infection and sepsis.

Sepsis is a common clinical problem with extremely high mortality rates. Several components of the immune system are implicated in the process of sepsis, including the release of proinflammatory mediators and activation of endothelial cells and polymorphonuclear leucocytes (PMN; Shimizu et al. 1992; Williams \& Hellewell, 1992). On activated endothelium, members of the Ig family of adhesion molecules intercellular adhesion molecules (ICAM) and vascular cell adhesion molecules (CAM) - are expressed. CAM are important in the adhesion of leucocytes to activated endothelium (Carlos \& Harlan, 1994). CD11a/CD18 and CD11b/CD18 are members of the leucocyte adhesion molecules- $\beta 2$ integrin. $\mathrm{CD} 11 \mathrm{a}$ and $\mathrm{CD} 11 \mathrm{~b}$ are thought to play central roles in mediating the firm adhesion of leucocytes to endothelial cells (Henderson et al. 2001). Overexpressions of adhesion molecules facilitate leucocyte-endothelial interactions which result in endothelial dysfunction and thus aggravate PMN accumulation and tissue damage (Ulbrich et al. 2003; Nolte et al. 2004). One study showed that plasma ICAM-1 levels increase in septic patients with multiple organ failure (Whalen et al. 2000). Also, plasma ICAM-1 in diabetic patients was significantly higher than that in healthy controls (Glowinska et al. 2005).

Fish oils are rich sources of $n-3$ PUFA, especially EPA and DHA. A number of clinical trials have shown that fish oil has immune modulatory effects (Grimm et al. 2002). The major advantages of $n-3$ fatty acids are related to their postulated reductions in proinflammatory effects. Several studies have shown that dietary fish oil has beneficial clinical effects on diseases including rheumatoid arthritis, inflammatory bowel diseases, multiple sclerosis and insulin-dependent diabetes mellitus (Calder, 1997, 2006). However, a previous study revealed that fish oil supplementation suppresses lymphocyte proliferation and has immunosuppressive properties (Virella et al. 1991). An ex vivo study also showed that $n-3$ fatty acids inhibit proliferative response and IL-2 production in lymphocytes obtained from diabetes mellitus patients (Alnajjar et al. 2006). In accordance with such observations,

Abbreviations: CAM, cellular adhesion molecule; CLP, caecal ligation and puncture; FO, fish oil group; ICAM, intercellular adhesion molecule; MPO, myeloperoxidase; PMN, polymorphonuclear leucocytes; SO, soyabean oil group.

* Corresponding author: Dr Sung-Ling Yeh, fax +8862 27361661 ext. 6551 115, email sangling@tmu.edu.tw 
laboratory animals fed fish oil exhibited lower survival and higher viable bacteria numbers than those fed other types of fat when infected with bacteria (Chang et al. 1992; Puertollano et al. 2004). Conflicting results were also observed in septic conditions when $n-3$ fatty acids were administered (Fritsche et al. 1997; Lanza-Jacoby et al. 2001). Most animal studies done previously were seldom performed with co-morbidities, the studies concerned with the influence of fish oil on the inflammatory response focused exclusively on the condition of diabetes mellitus or sepsis. Studies investigating the effects of dietary fish oil on diabetes mellitus complicated with sepsis are rare. Therefore, we induced polymicrobial sepsis after treating diabetic mice with fish oil to investigate the effect of $n-3$ fatty acids on adhesion molecules and inflammatory cytokines in diabetic mice complicated with sepsis. Because oxyradicals released from leucocytes that accumulate in organs may damage organ cells and induce organ dysfunction (Klebanoff \& Seymour, 2005), we analysed the myeloperoxidase (MPO) activities in organs as an indicator for identifying the extent of tissue injury resulting from diabetes mellitus with sepsis.

\section{Materials and methods}

\section{Animals}

Male ICR mice weighing approximately 25-30g were purchased from the Animal Center of National Taiwan University, College of Medicine. Mice were maintained in a temperature-controlled $\left(23 \pm 2^{\circ} \mathrm{C}\right)$ and humidity-controlled $(55 \pm 15 \%)$ room with a $12 \mathrm{~h}$ light-dark cycle. All mice were allowed free access to a standard chow diet and water for 1 week before the study. Care of the laboratory animals was established by Taipei Medical University, and protocols were approved by the Animal Committee. Diabetes was induced in the mice by a single intraperitoneal injection of streptozotocin (Sigma Chemical Co., St Louis, MO, USA) at a dose of $150 \mathrm{mg} / \mathrm{kg}$ body weight as previously described by Oguri et al. (2003). Streptozotocin was dissolved immediately before use in saline to a concentration of $15 \mathrm{mg} / \mathrm{ml}$. Three days later, blood was obtained by piercing a needle into the tail vein of the mice; it was directly applied on to a strip of a blood glucose monitor to determine the glucose levels. Mice were considered diabetic only if their blood glucose levels exceeded $2000 \mathrm{mg} / \mathrm{l}$ (Ackerman \& Leibman, 1977). The average blood glucose levels for normal mice were 1195 (SD 124) mg/l ( $n$ 8). Diabetic mice were not treated with insulin in the present study.

\section{Experimental design and procedures}

The diabetic mice were divided into two groups according to the weight and blood glucose of the animals to make average weights and blood glucose levels among groups as similar as possible. All mice were maintained for 3 weeks on a mediumfat $(10 \%, w / w)$ semi-purified diet. The diets fed to the two experimental groups were identical except for the sources of the fat (Table 1). The soyabean oil group ( $\mathrm{SO}, n$ 30) was exclusively fed soyabean oil (Taiwan Sugar Co., Taipei, Taiwan), while the fish oil group (FO, $n$ 30) had $23 \%$ fish oil (Denofa Co., Fredrikstad, Norway) and $77 \%$ soyabean oil (Table 1). The fish oil contained $34 \%$ EPA, $27 \%$ DHA
Table 1. Composition of the experimental diets $(\mathrm{g} / \mathrm{kg})$

\begin{tabular}{lcc}
\hline Component & Soyabean oil group & Fish oil group \\
\hline Soyabean oil & 100 & 77 \\
Fish oil & 0 & 23 \\
Casein & 200 & 200 \\
Maize starch & 620 & 620 \\
Salt mixture & 35 & 35 \\
Vitamin mixture§ & 10 & 10 \\
Methyl cellulose & 31 & 31 \\
Choline chloride & 1 & 1 \\
Methionine & 3 & 3
\end{tabular}

$\ddagger$ The salt mixture contained the following $(\mathrm{mg} / \mathrm{g})$ : calcium phosphate diabasic, 500; sodium chloride, 74; potassium sulphate, 52; potassium citrate monohydrate, 20; magnesium oxide, 24; manganese carbonate, 3.5; ferric citrate, 6; zinc carbonate, 1.6; cupric carbonate, 0.3; potassium iodate, 0.01 ; sodium selenite, 0.01 ; and chromium potassium sulphate, 0.55 .

$\S$ The vitamin mixture contained the following $(\mathrm{mg} / \mathrm{g})$ : thiamin hydrochloride, 0.6 ; ricoflavin, 0.6 ; pyridoxine hydrochloride, 0.7 ; nicotinic acid, 3; calcium pantothenate, 1.6; D-biotin, 0.05 ; cyanocobalamin, 0.001 ; retinyl palmitate, 1.6; DL- $\alpha$-tocopherol acetate, 20; cholecalciferol, 0.25; menaquinone, 0.005.

and $72 \%$ total $n-3$ fatty acids, while the mixed tocopherols was $2.4 \mathrm{mg} / \mathrm{g}$. The soyabean oil contained $6.5 \% n-3$ fatty acids and $55 \% n-6$ fatty acids according to the manufacturer. The $n-3 / n-6$ ratio in the FO diet was $1: 2$ in the present study. After feeding the respective diet for 3 weeks, polymicrobial sepsis was induced in the mice. Sepsis was induced by caecal ligation and puncture (CLP) according to the method of Ayala et al. (1994). Briefly, mice were lightly anaesthetized with diethyl ether and their abdomens were opened through a midline incision below the diaphragm. The caecum was isolated and ligated just below the ileocaecal valve. The caecum was then punctured twice with a 22-gauge needle and was slightly compressed until a small drop of stool appeared. After CLP was performed, the caecum was replaced into the abdominal cavity and the wound was closed in layers. Diabetes mellitus-sepsis mice were killed at 0,6 and $24 \mathrm{~h}$ after the CLP, with ten mice at each time-point. Mice in $0 \mathrm{~h}$ groups were killed immediately after CLP. All mice were anaesthetized with intraperitoneal pentobarbital sodium $(50 \mathrm{mg} / \mathrm{kg}$ body weight) and were killed by heart puncture. The abdomen was opened and the peritoneal cavity was lavaged with $2 \mathrm{ml}$ PBS. The peritoneal lavage fluid was collected for TNF- $\alpha$ and $\mathrm{PGE}_{2}$ analyses. Fresh blood samples were collected in tubes containing EDTA- $\mathrm{Na}_{2}$ for analysing leucocyte $\mathrm{CD} 11 \mathrm{a} / \mathrm{CD} 18$ and $\mathrm{CD} 11 \mathrm{~b} / \mathrm{CD} 18$ expressions. Plasma samples were stored at $-80^{\circ} \mathrm{C}$ until glucose and ICAM-1 was measured. Tissues including the liver, kidneys, intestines and lungs were rapidly harvested and stored at $-80^{\circ} \mathrm{C}$ for the measurement of MPO activities.

\section{Measurements and analytical procedures}

Measurements of plasma glucose and intercellular adhesion molecule-1 concentrations. Glucose levels were determined by colorimetric methods after an enzymatic reaction with peroxidase (Randox Co., Antrim, Ireland). Procedures followed the manufacturer's instructions. Concentrations of ICAM were measured by using a commercially available ELISA kit (R\&D Systems, Minneapolis, MN, USA). Antibodies specific 
for mouse ICAM-1 were coated on to the wells of the microtitre strips provided. The minimum detectable dose for ICAM1 was $17 \mathrm{pg} / \mathrm{ml}$. The within-assay $\mathrm{CV}$ was $6 \cdot 3 \%$ in the present study.

Measurement of TNF- $\alpha$ and $P G E_{2}$ levels in peritoneal lavage fluid. Concentrations of $\mathrm{TNF}-\alpha$ were measured using a commercially available ELISA. Antibodies specific for mouse TNF- $\alpha$ were coated on to the wells of the microtitre strips provided (R\&D Systems). $\mathrm{PGE}_{2}$ concentrations were also measured by ELISA. The surfaces of the microtitre plates were precoated with mouse monoclonal antibody. Acetylcholinesterase covalently coupled to $\mathrm{PGE}_{2}$ was used as the enzymatic tracer (R\&D Systems). The detection limit for TNF- $\alpha$ was $5.1 \mathrm{pg} / \mathrm{ml}$ and for $\mathrm{PGE}_{2}$ was $8.5 \mathrm{pg} / \mathrm{ml}$. The within-assay $\mathrm{CV}$ for TNF- $\alpha$ and $\mathrm{PGE}_{2}$ were $6.8 \%$ and $7 \cdot 2$, respectively.

Analysis of the CD11a/CD18 distribution in lymphocytes and CD11b/CD18 in polymorphonuclear leucocytes. Lymphocytes and PMN in blood were gated on the basis of the forward scatter and side scatter profiles by flow cytometry (Coulter, Miami, FL, USA), and were analysed for the expressions of CD11a/CD18 and CD11b/CD18, respectively. Fresh blood $(100 \mu \mathrm{l})$ was incubated with $10 \mu \mathrm{l}$ fluorescent isothiocynate-conjugated rat monoclonal anti-mouse CD11a (I21/7) and phycoerthrin-conjugated rat monoclonal anti-mouse CD18 (C71/16; Serotec, Oxford, UK) for $15 \mathrm{~min}$ at $4^{\circ} \mathrm{C}$. Fluorescent isothiocynate-conjugated rat $\mathrm{IgG} 2 \mathrm{a}$ and phycoerthrin-conjugated rat $\mathrm{IgG} 2 \mathrm{a}$ were used for isotope control (Serotec). Subsequently, erythrocytes were lysed with lysing buffer (Serotec). The percentages of CD11a/CD18 expressed on lymphocytes were analysed by flow cytometry. Fluorescence data were collected and the results are presented as a percentage of CD11a-presenting cells in $1 \times 10^{5}$ lymphocytes. To measure CD11b/CD18 expressions on PMN, fluorescent isothiocynate-conjugated rat monoclonal anti-mouse CD11b (M1/70.15) and phycoerthrin-conjugated rat monoclonal anti-mouse CD18 (C71/16; Serotec) were added into $100 \mu \mathrm{l}$ fresh blood. Fluorescent isothiocynate-conjugated rat $\mathrm{IgG} 2 \mathrm{~b}$ and phycoerthrin-conjugated rat IgG2a were used for isotope control (Serotec). Fluorescence data were collected on $1 \times 10^{5} \mathrm{PMN}$ which were also analysed by flow cytometry. The results are presented as a percentage of CD11b/CD18 expression in $1 \times 10^{5} \mathrm{PMN}$. Non-specific fluorescence was determined on cells incubated with isotype and fluorochrome-matched control antibodies (Hsu et al. 2006).

Measurement of myeloperoxidase activity in organs. The method of measuring MPO activity was modified as previously described (Hillegass et al. 1990). Tissue samples were homogenized in $50 \mathrm{~mm}$-potassium phosphate buffer (pH 6.0), and centrifuged at $2000 \mathrm{~g}$ at $4^{\circ} \mathrm{C}$ for $15 \mathrm{~min}$. After discarding the supernatant, the pellets were suspended in a solution containing $0.5 \%$ hexadecyl-trimethyl-ammonium bromide dissolved in potassium phosphate buffer $(\mathrm{pH} 7.0)$ and centrifuged for $30 \mathrm{~min}$ at $15000 \mathrm{~g}$ and $4^{\circ} \mathrm{C}$. An aliquot of the supernatant was then allowed to react with a solution of tetra-methyl-benzidine $(1.6 \mathrm{~mm})$ and $0.1 \mathrm{~mm}-\mathrm{H}_{2} \mathrm{O}_{2}$. The absorbance at $650 \mathrm{~nm}$ was measured for $3 \mathrm{~min}$ and the rate of change in the absorbance was used to calculate the activities of MPO. MPO activity was defined as the quantity of enzyme degrading $1 \mu \mathrm{mol}$ peroxide per min at $37^{\circ} \mathrm{C}$ and the data were expressed in units/g wet tissue.

\section{Statistical analysis}

Data are expressed as means and standard deviations. All statistical analyses were performed with SigmaStat version 3.1 software (SYSTAT Software Inc., Chicago, IL, USA). Differences among groups were analysed by two-way ANOVA using Fisher's post hoc test. $P<0.05$ was considered statistically significant.

\section{Results}

Body weights and plasma glucose levels

There were no differences in the initial body weights and body weights after feeding the respective diets for 3 weeks between the two experimental groups (data not shown). There were no differences in fasting plasma glucose concentrations between the FO and SO groups at various time-points after CLP (Table 2).

\section{Plasma intercellular adhesion molecule-1 levels}

Plasma ICAM-1 levels were higher at $24 \mathrm{~h}$ than 0 and $6 \mathrm{~h}$ after CLP in both groups $(P<0.001$ for time effect). There were no differences in ICAM-1 concentrations between the SO and FO groups at various time-points after CLP (Fig. 1).

\section{$P G E_{2}$ and TNF- $\alpha$ concentrations in peritoneal lavage fluid}

The $\mathrm{PGE}_{2}$ levels in the FO groups were significantly lower than in the SO groups at each time-point after CLP $\left(P<0.001\right.$ for diet effect). The $\mathrm{PGE}_{2}$ levels were lower at $0 \mathrm{~h}$ than at 6 and $24 \mathrm{~h}$ after CLP in both groups $(P<0.001$ for time effect; Fig. 2(A)). Concentrations of TNF- $\alpha$ increased with the progression of sepsis in the SO group, whereas no differences were found among the $\mathrm{FO}$ groups at various time-points $(P<0.001$ for time effect). The SO group had higher TNF- $\alpha$ concentrations than the FO group $24 \mathrm{~h}$ after CLP $(P=0.039$ for diet effect, $P=0.013$ for diet and time interaction; Fig. 2(B)).

Table 2. Plasma glucose concentrations ( $\mathrm{mg} / \mathrm{l})$ of the fish oil group (FO) and the soyabean oil group (SO)‡

(Mean values and standard deviations)

\begin{tabular}{llr}
\hline & \multicolumn{2}{c}{ Fasting blood glucose } \\
\cline { 2 - 3 } & Mean & SD \\
\hline Oh & & \\
FO & 2512 & 477 \\
SO & 3380 & 1082 \\
$6 \mathrm{~h}$ & & \\
FO & 2920 & 920 \\
SO & 2803 & 779 \\
$24 \mathrm{~h}$ & & 361 \\
FO & 2626 & 1139 \\
SO & 3047 & \\
\hline F For details of procedures, see Materials and methods \\
section.
\end{tabular}




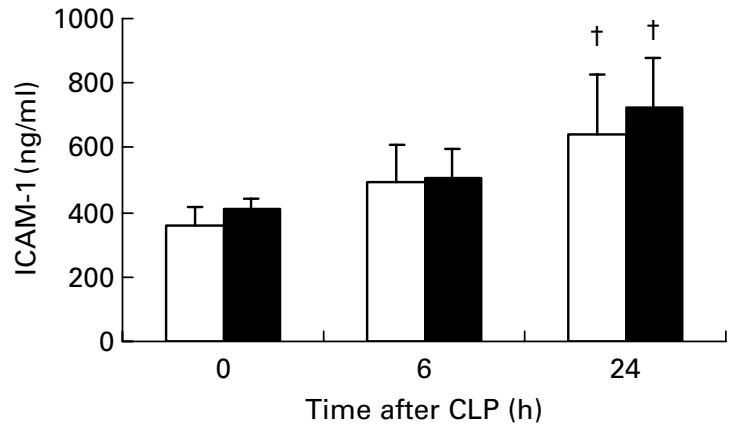

Fig. 1. Plasma intercellular adhesion molecule-1 (ICAM-1) levels in the fish oil group ( $\square$ ) and the soyabean oil group ( $\square$ ). For details of procedures, see Materials and methods section. Values are means with their standard deviation depicted by vertical bars. Mean values were significantly different from those of the other time-points in the same group: $† P<0.05$. CLP, caecal ligation and puncture.

\section{Expressions of CD11a/CD18 on lymphocytes and CD11b/ CD18 on polymorphonuclear leucocytes}

CD11a/CD18 expressions on lymphocytes were higher at $6 \mathrm{~h}$, whereas the percentage was lower at $24 \mathrm{~h}$ in the SO group than in the FO group. SO groups had the highest CD11a expression at $6 \mathrm{~h}$, while the highest CD11a percentage was found at $24 \mathrm{~h}$ after CLP in the FO group $(P=0.001$ for time effect, $P<0.001$ for diet and time interaction; Fig. 3(A)). The expressions of CD11b/CD18 on PMN decreased in the SO group as sepsis progressed. CD11b/CD18 expressions were significantly higher in the SO group than in the FO group at $0 \mathrm{~h}$. There
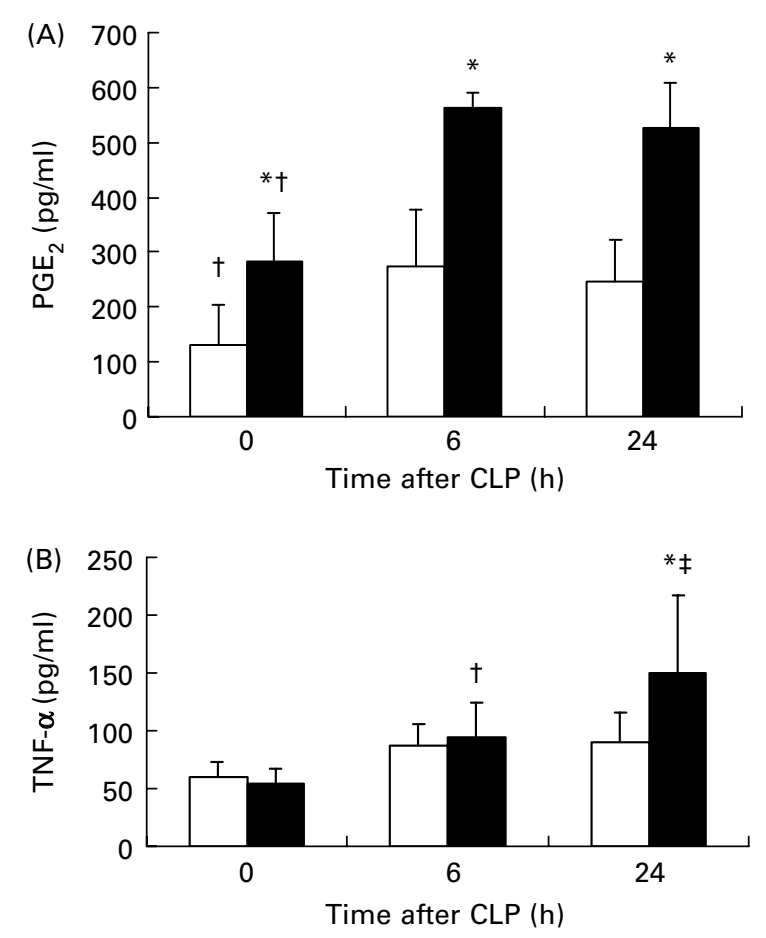

Fig. 2. Concentrations of $P G E_{2}(A)$ and $T N F-\alpha(B)$ in peritoneal lavage fluid in the fish oil group (FO, $\square$ ) and the soyabean oil group ( $\square$ ). For details of procedures, see Materials and methods section. Values are means with their standard deviation depicted by vertical bars. Mean values were significantly different from those of the the FO group at the same time point: ${ }^{*} P<0.05$. Mean values were significantly different from those of the other time-points in the same group: $\dagger P<0.05 ; \ddagger P<0.001$. CLP, caecal ligation and puncture.

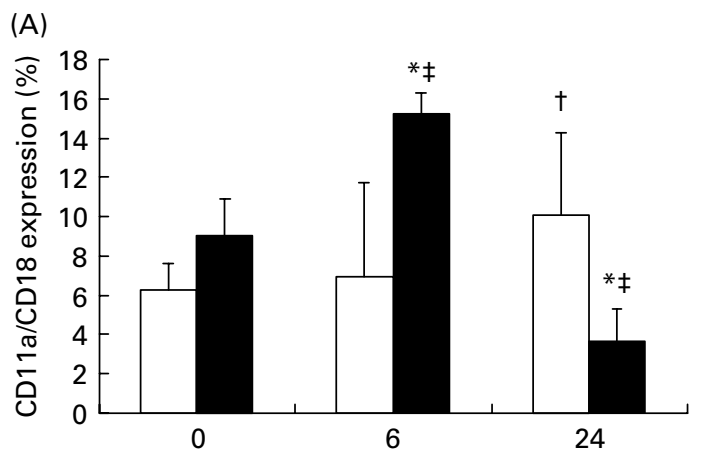

Time after CLP (h)

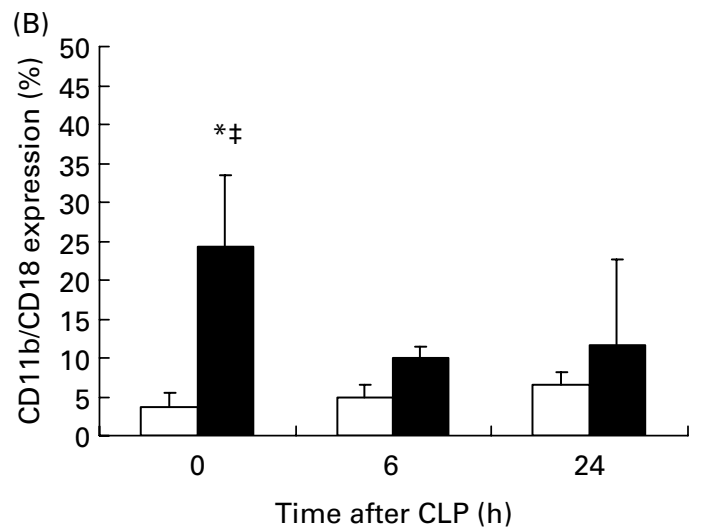

Fig. 3. Expressions of lymphocyte CD11a/CD18 (A) and neutrophil CD11b/CD18 (B) in the in the fish oil group (FO, $\square$ ) and the soyabean oil group (ם). For details of procedures, see Materials and methods section. Values are means with their standard deviation depicted by vertical bars. * Significantly different from the FO group at the same time point. Mean values were significantly different from those of the the FO group at the same time point: ${ }^{\star} P<0.05$. Mean values were significantly different from those of the other time-points in the same group: $† P<0.05 ; \ddagger P<0.001$. CLP, caecal ligation and puncture.

were no differences in the expressions of CD11b/CD18 among the various FO groups $(P<0.001$ for diet effect, $P=0.006$ for time effect, $P<0.001$ for diet and time interaction; Fig. 3(B)).

\section{Myeloperoxidase activities in the liver, lungs, kidneys and intestines}

The activities of MPO increased as sepsis progressed and reached a peak at different time-points depending on the type of oil in various organs. The FO groups had lower MPO activities at $0 \mathrm{~h}$ in the liver, at 0 and $6 \mathrm{~h}$ in the kidneys, and at $24 \mathrm{~h}$ after CLP in the lungs compared with those in the SO groups $(P<0 \cdot 05$; Table 3$)$.

\section{Discussion}

In the present study, $n-3$ fatty acids provided $4.3 \%$ of the total energy in the FO diet. This amount of $n-3$ fatty acids is comparable to values used in studies with beneficial results, which showed that $n-3$ fatty acid supplementation reduced inflammatory-related mediators and improved survival in rodents in a CLP model (Johnson et al. 1993; Lanza-Jacoby et al. 2001). The $n-3 / n-6$ ratio was adjusted to $1: 2$, because this ratio was 
Table 3. Myeloperoxidase activities ( $\mathrm{U} / \mathrm{g}$ tissue) in organ homogenates of the fish oil group (FO) and the soyabean oil group (SO)‡

(Mean values and standard deviations)

\begin{tabular}{|c|c|c|c|c|c|c|c|c|}
\hline & \multicolumn{2}{|c|}{ Liver } & \multicolumn{2}{|c|}{ Kidneys } & \multicolumn{2}{|c|}{ Intestines } & \multicolumn{2}{|c|}{ Lungs } \\
\hline & Mean & SD & Mean & SD & Mean & SD & Mean & SD \\
\hline \multicolumn{9}{|l|}{$\mathrm{Oh}$} \\
\hline FO & $2 \cdot 62^{\star}$ & 0.98 & $6 \cdot 30^{*} \dagger$ & 1.49 & 0.49 & 0.30 & $4 \cdot 84$ & 1.92 \\
\hline so & 4.75 & 0.95 & $9.01 \dagger$ & 1.69 & 0.80 & 0.18 & $5 \cdot 33$ & $2 \cdot 30$ \\
\hline \multicolumn{9}{|l|}{$6 \mathrm{~h}$} \\
\hline $\mathrm{FO}$ & $4.05 \dagger$ & 1.26 & $9 \cdot 30^{*}$ & 2.04 & 0.88 & 0.25 & 4.71 & 0.81 \\
\hline so & 4.96 & 1.44 & $12 \cdot 5$ & 1.85 & 0.92 & 0.34 & $6.78 \dagger$ & 2.43 \\
\hline \multicolumn{9}{|l|}{$24 \mathrm{~h}$} \\
\hline FO & $2 \cdot 31$ & 0.75 & $13 \cdot 4$ & 3.99 & 0.71 & 0.17 & $3 \cdot 85^{\star}$ & 1.48 \\
\hline so & $2.75+$ & 0.62 & $12 \cdot 4$ & 2.89 & 0.85 & 0.47 & $10.0+\dagger$ & 2.55 \\
\hline \multicolumn{9}{|c|}{$P$ value of the effects } \\
\hline Diet effect & 0.047 & & 0.001 & & 0.121 & & $<0.001$ & \\
\hline Time effect & $<0.001$ & & $<0.001$ & & 0.148 & & 0.088 & \\
\hline Diet $\times$ Time & 0.073 & & 0.093 & & 0.536 & & 0.005 & \\
\hline
\end{tabular}

Mean values were significantly different from those of the SO group at the same time-point: ${ }^{\star} P<0.05$.

Mean values were significantly different from those of the other time-points in the same groups: $\uparrow P<0.05 ; \dagger \uparrow P<0.001$ ‡For details of procedures, see Materials and methods section.

considered to exert the most favourable modulation of lipid mediator synthesis (Morlion et al. 1997). In the present study, we used streptozotocin to induce diabetes, a model frequently used to stimulate non-insulin-dependent diabetes in animal studies (Chyi \& Yeh, 2000), and CLP is a clinically relevant model of gut-derived sepsis in mice (Maier et al. 2004).

$\mathrm{PGE}_{2}$ is a product of arachidonic acid metabolism. Numerous studies have shown that an increased dietary intake of $n-3$ fatty acids suppresses $\mathrm{PGE}_{2}$ synthesis (Mayatepek et al. 1994; Calder, 2006). The previous results are in good agreement with the present finding that diabetic mice fed FO had lower $\mathrm{PGE}_{2}$ levels than those fed SO after CLP. TNF- $\alpha$ is an important mediator involved in the onset and regulation of inflammatory and immune response. Circulating TNF- $\alpha$ is associated with significant pathologic change, possibly leading to mortality (DiPiro, 1997), suggesting that the TNF- $\alpha$ synthesis must be controlled. A study by Blok et al. (1996) showed that the plasma TNF- $\alpha$ concentration was significantly increased in mice fed $n-3$ fatty acids. A previous study performed by our laboratory also showed that compared with safflower oil, feeding diabetes mellitus-sepsis rats with FO produced lower $\mathrm{PGE}_{2}$ and higher TNF- $\alpha$ in peritoneal lavage fluid (Chyi \& Yeh, 2000). These earlier results are inconsistent with the findings in the present study that the TNF- $\alpha$ concentrations in peritoneal lavage fluid paralleled the $\mathrm{PGE}_{2}$ concentrations in diabetes mellitus-sepsis mice with FO administration. Those studies which found elevated TNF- $\alpha$ levels provided more than $10 \%$ of total energy as $n-3$ fatty acids, while in the present study, a relatively lower dose of $n-3$ fatty acids was administered. It is possible that, although $\mathrm{PGE}_{2}$ was suppressed, the amount of $n-3$ fatty acids used in the present study was not sufficiently potent to enhance excessive TNF- $\alpha$ production.

CD11a/CD18 are exclusively expressed on leucocytes and CD11b/CD18 are abundant in PMN (Henderson et al. 2001). We analysed lymphocyte CD11a/CD18 expression in the present study, because the function of $\mathrm{T}$ lymphocyte subsets is important on influencing the type of immunity and the inflammatory response to diabetes mellitus-sepsis (DiPiro, 1997). CD11a is important for lymphocyte trafficking and activation. Although lymphocytes constitute a relatively small population of the total lymphocyte pool in normal conditions (Westermann \& Pabst, 1990), the total numbers of lymphocyte subsets in blood were greatly increased under inflammatory conditions. In the present study we found that compared with the diabetic mice fed SO, FO administration resulted in lower CD11a and CD11b expressions in the early stage of sepsis. An in vitro study showed that endothelial cells treated with $n-3$ fatty acids inhibited cytokine-induced expression of adhesion molecules (De Caterina \& Libby, 1996). A study by Miles et al. (2000) showed that dietary FO reduced CAM expression by murine peritoneal macrophages. The findings of the present study suggest that leucocyte adhesion and migration may be attenuated when FO is administered in a diabetes mellitus-sepsis condition.

ICAM-1 is a cell surface protein expressed on the vascular endothelium. ICAM-1 and its ligands CD11a and CD11b are important mediators of host defence localized in the earliest lesions of inflammation (Weber, 2003). In the present study, we observed that plasma ICAM-1 levels increased as sepsis progressed, however, the changes in plasma ICAM-1 were inconsistent with the alteration in the integrin expressed on leucocytes. Since ICAM-1 plays an important role in transendothelial migration of leucocytes, we speculate that blood leucocytes have transmigrated into the tissue especially at the late stage of sepsis so that only limited amounts of leucocytes can be measured in the blood.

MPO is an enzyme synthesized by neutrophil and monocyte precursor cells. MPO plays an important role in leucocytemediated vascular injury responses in inflammatory vascular diseases (Klebanoff \& Seymour, 2005). Previous studies showed that MPO activities increased in vessels of diabetic rats (Zhang et al. 2004) and in type 2 diabetic patients (Moldoveanu et al. 2006). Also, a study performed by our laboratory found that MPO activities increased in the lungs, 
liver, intestines and kidneys at an early stage of sepsis (Hsu et al. 2006). In the present study, we found that FO administration resulted in lower MPO activities in the liver, kidneys and lungs at 0,6 or $24 \mathrm{~h}$ after sepsis in diabetic mice. The present finding may indicate that diabetic mice with FO administration have less neutrophil infiltration in these organs after sepsis. A previous study showed that proinflammatory cytokines upregulate CAM expression (Myers et al. 1992). It is possible that FO decreased proinflammatory cytokine production and thus decreased CAM expression and neutrophil migration.

In summary, the present study demonstrated that diabetic mice with low-dose $n$-3 fatty acid supplementation resulted in lower $\mathrm{PGE}_{2}$ and TNF- $\alpha$ levels after CLP. Also, leucocyte CD11a and CD11b expressions and MPO activities in various organs were decreased at different time-points after sepsis when FO was administered. The present findings suggest that dietary FO supplementation may attenuate leucocyte adhesion and infiltration into tissues, thus producing a favourable effect in diabetic mice complicated with sepsis.

\section{Acknowledgements}

This study was supported by research grant NSC95-2320-B038-042 from the National Science Council, ROC.

\section{References}

Ackerman DM \& Leibman KC (1977) Effect of experimental diabetes on drug metabolism in the rat. Drug Metab Dispos 5, 405-410.

Alnajjar A, Sari DC, Abuharfeil N, Hudaib M \& Aburjai T (2006) Effect of n-3 and n-6 polyunsaturated fatty acids on lymphocyte proliferation, interleukin production and phospholipid fatty acids composition in type 2 diabetic and heathy subjects in Jordan people. Prostaglandins Leukot Essent Fatty Acids 74, 347-356.

Ayala A, Deol ZK, Lehman DL, Herdon CD \& Chaudry IH (1994) Polymicrobial sepsis but not low-dose endotoxin infusion causes decreased splenocyte IL-2/IFN-gamma release while increasing IL-4/IL-10 production. $J$ Surg Res 56, 579-585.

Blok WL, de Bruijn MFTR, Leenen PJM, Eling WMC, van Rooijen N, Stanley ER, Buurman WA \& van der Meer JWM (1996) Dietary $n-3$ fatty acids increase spleen size and postendotoxin circulating TNF in mice; role of macrophages, macrophage precursors, and colony-stimulating factor-1. J Immunol 157, 5569-5573.

Calder PC (1997) n-3 polyunsaturated fatty acids as pharmacologic agents: a fishy tale? Nutrition 13, 1002-1004.

Calder PC (2006) n-3 polyunsaturated fatty acids, inflammation, and inflammatory diseases. Am J Clin Nutr 83, suppl., 1505S-1519S.

Carlos TM \& Harlan JM (1994) Leukocyte-endothelial adhesion molecules. Blood 84, 2068-2101.

Chang HR, Dulloo AG, Vladoianu IR, Piguet PF, Arsenijevic D, Girardier L \& Pechere JC (1992) Fish oil decreases natural resistance of mice to infection with Salmonella typhimurium. Metabolism 41, 1-2.

Chyi AC \& Yeh SL (2000) Effects of dietary fish oil on survival rate, plasma amino acid pattern, and inflammatory-related mediators in diabetic rats with sepsis. Clin Nutr 19, 313-318.

De Caterina R \& Libby P (1996) Control of endothelial leukocyte adhesion molecules by fatty acids. Lipids 31, Suppl., S57-S63.

Department of Health, Taiwan (2005) Top 10 leading causes of death in Taiwan. (www.doh.gov.tw).
DiPiro JT (1997) Cytokine networks with infection: mycobacterial infections, leishmaniasis, human immunodeficiency virus infection, and sepsis. Pharmacotherapy 17, 205-223.

Fritsche KL, Shahbazian LM, Feng C \& Berg JN (1997) Dietary fish oil reduces survival and impairs bacterial clearance in $\mathrm{C} 3 \mathrm{H} / \mathrm{Hen}$ mice challenged with Listeria monocytogenes. Clin Sci (Lond) 92, 95-101.

Glowinska B, Urban M, Peczynska J \& Florys B (2005) Soluble adhesion molecules (sICAM-1, sVCAM-1) and selectins (sE selectin, sP selectin, sL selectin) levels in children and adolescents with obesity, hypertension, and diabetes. Metabolism 54, 1020-1026.

Grimm H, Mayer K, Mayser P \& Eigenbrodt E (2002) Regulatory potential of $n-3$ fatty acids in immunological and inflammatory processes. Br J Nutr 87, Suppl. 1, S59-S67.

Henderson RB, Lim LH, Tessier PA, Gavins FN, Mathies M, Perretti M \& Hogg N (2001) The use of lymphocyte function-associated antigen (LFA)-1-deficient mice to determine the role of LFA-1, Mac-1, and alpha4 integrin in the inflammatory response of neutrophils. J Exp Med 194, 219-226.

Hillegass LM, Griswold DE, Brickson B \& Albrightson-Winslow C (1990) Assessment of myeloperoxidase activity in whole rat kidney. J Pharmacol Meth 24, 285-295.

Hsu CS, Chiu WC, Yeh CL, Hou YC, Chou SY \& Yeh SL (2006) Dietary fish oil enhances adhesion molecule and interleukin-6 expression in mice with polymicrobial sepsis. $B r J$ Nutr 96, 854-860.

Johnson JA 3rd, Griswold JA \& Muakkassa FF (1993) Essential fatty acids influence survival in sepsis. J Trauma 35, 128-131.

Klebanoff SJ \& Seymour J (2005) Myeloperoxidase: friend and foe. J Leukoc Biol 77, 598-625.

Lanza-Jacoby S, Flynn JT \& Miller S (2001) Parenteral supplementation with a fish-oil emulsion prolongs survival and improves rat lymphocyte function during sepsis. Nutrition 17, 112-116.

Maier S, Traeger T, Entleutner M, Westerholt A, Kleist B, Huser N, Holzmann B, Stier A, Pfeffer K \& Heidecke CD (2004) Cecal ligation and puncture versus colon ascendens stent peritonitis: two distinct animal models for polymicrobial sepsis. Shock 21, 505-511.

Mayatepek E, Paul K, Leichsenring M, Pfisterer M, Wagner D, Domann M, Sonntag HG \& Bremer HJ (1994) Influence of dietary (n-3)-polyunsaturated fatty acids on leukotriene B4 and prostaglandin E2 synthesis and course of experimental tuberculosis in guinea pigs. Infection 22, 106-112.

Miles EA, Wallace FA \& Calder PC (2000) Dietary fish oil reduces intercellular adhesion molecule 1 and scavenger receptor expression on murine macrophages. Atherosclerosis 152, 43-50.

Moldoveanu E, Tanaseanu C, Tanaseanu S, Kosaka T, Manea G, Marta DS \& Popescu LM (2006) Plasma markers of endothelial dysfunction in type 2 diabetics. Eur J Intern Med 17, 38-42.

Morlion BJTE, Wrenger K, Puchsiein C \& Furst P (1997) What is the optimum n-3 to n-6 fatty acid ratio of parenteral lipid emulsions in postoperative trauma? Clin Nutr 16, 49S.

Myers CL, Wertheimer SJ, Schembri-King J, Parks T \& Wallace RW (1992) Induction of ICAM-1 by TNF-alpha, IL-1 beta, and LPS in human endothelial cells after downregulation of PKC. Am J Physiol 263, C767-C772.

Nolte D, Kuebler WM, Muller WA, Wolff KD \& Messmer K (2004) Attenuation of leukocyte sequestration by selective blockade of PECAM-1 or VCAM-1 in murine endotoxemia. Eur Surg Res 36, 331-337.

Nystrom T, Nygren A \& Sjoholm A (2006) Increased levels of tumour necrosis factor-alpha (TNF-alpha) in patients with type II diabetes mellitus after myocardial infarction are related to endothelial dysfunction. Clin Sci (Lond) 110, 673-681.

Oguri S, Motegi K \& Endo Y (2003) Augmented lipopolysaccharideinduction of the histamine-forming enzyme in streptozotocininduced diabetic mice. Biochim Biophys Acta 1637, 83-90. 
Parillo M \& Riccardi G (2004) Diet composition and the risk of type 2 diabetes: epidemiological and clinical evidence. Br J Nutr 92, 7-19.

Puertollano MA, Puertollano E, Ruiz-Bravo A, Jimenez-Valera M, De Pablo M \& De Cienfuegos GA (2004) Changes in the immune functions and susceptibility to Listeria monocytogenes infection in mice fed dietary lipids. Immunol Cell Biol 82, 370-376.

Shimizu Y, Newman W, Tanaka Y \& Shaw S (1992) Lymphocyte interactions with endothelial cells. Immunol Today 13, 106-112.

Ulbrich H, Eriksson EE \& Lindbom L (2003) Leukocyte and endothelial cell adhesion molecules as targets for therapeutic interventions in inflammatory disease. Trends Pharmacol Sci 24, 640-647.

Virella G, Fourspring K, Hyman B, Haskill-Stroud R, Long L, Virella I, La Via M, Gross AJ \& Lopes-Virella M (1991) Immunosuppressive effects of fish oil in normal human volunteers: correlation with the in vitro effects of eicosapentanoic acid on human lymphocytes. Clin Immunol Immunopathol 61, 161-176.
Weber C (2003) Novel mechanistic concepts for the control of leukocyte transmigration: specialization of integrins, chemokines, and junctional molecules. J Mol Med 81, 4-19.

Westermann J \& Pabst R (1990) Lymphocyte subsets in the blood: a diagnostic window on the lymphoid system? Immunol Today 11, 406-409.

Whalen MJ, Doughty LA, Carlos TM, Wisniewski SR, Kochanek PM \& Carcillo JA (2000) Intercellular adhesion molecule-1 and vascular cell adhesion molecule-1 are increased in the plasma of children with sepsis-induced multiple organ failure. Crit Care Med 28, 2600-2607.

Williams TJ \& Hellewell PG (1992) Endothelial cell biology. Adhesion molecules involved in the microvascular inflammatory response. Am Rev Respir Dis 146, S45-S50.

Zhang C, Yang J \& Jennings LK (2004) Leukocyte-derived myeloperoxidase amplifies high-glucose-induced endothelial dysfunction through interaction with high-glucose-stimulated, vascular non-leukocyte-derived reactive oxygen species. Diabetes 53, 2950-2959. 